\title{
A Comparative Genre Analysis of Schematic Structures in Public Speeches of Native and Nonnative English Speakers ${ }^{\mathrm{i}}$
}

\author{
Chang Wang \\ School of Foreign Languages, Northeast Normal University, China
}

Copyright $(2016$ by authors, all rights reserved. Authors agree that this article remains permanently open access under the terms of the Creative Commons Attribution License 4.0 International License

\begin{abstract}
English speech writing has constituted an increasingly important part of pedagogical contents in the university education of China. As a specific genre, public speeches are diversified in accordance with speakers' specific communicative purposes, which are realized through the application of different schematic structures. It is found that native English speakers and EFL learners in China differ in their persuasive writing in the arrangement of strategic constituents of the speech macrostructure which is made up of moves and steps. Even though the three obligatory moves are predetermined for the structural completeness of the speech writing, steps are of great flexibility and creativity. Since influences from the cultural norms of Chinese are inevitable, a distinction between inductive and deductive ways of reasoning has been recognized. However, the dichotomy between the two patterns of thinking in different cultures has been proven complementary. Thus, it is proposed that developing students' sensitivity and ability in identifying communicative purposes of specific genres, inspiring them to be creative in schematic structures and breaking the prescriptive way of teaching and learning will be of great significance in future public speaking classes.
\end{abstract}

Keywords Public Speeches, Schematic Structure, Move, Step, EFL Learner, Genre Analysis

\section{Introduction and Research Questions}

Public speaking can be an effective way of learning a foreign language since it is not only practical but conducive to a good command of English in general. However, public speaking is much demanding. Taking place in different situations and in different forms, public speaking becomes a most effective but challenging means of information transmission. Once the difficulty in public speaking can be overcome, great progress in language acquisition will be achieved and students will find their English distinctively improved and will speak with more ease and confidence when expressing themselves in English in different contexts.

Speech, like all other modes of communication, is essentially a social activity since it has developed as a means of social adjustment, social integration and social control. Language used in public speeches must be effective. As speakers, students should first of all strive to make themselves understood and meanwhile remove syntactic ambiguity. Quite often, speakers will try hard to impress upon others mutual experiences, attitudes and feelings. They emphasize on the degree to which they are able to integrate themselves into their audience's social environment and to get people to think, feel and act as they want them. Thus, how to organize messy and multidimensional speech materials into orderliness and rationality constitute a key concern for speakers.

The relevance of speech materials itself does not guarantee success. In order to achieve the due effectiveness in the speeches, speakers have to carefully organize and arrange those materials into a certain pattern which can make their propositions easy to be accepted. Effective speech should be analytical and impressive, claiming the attention and interest of the listeners. Without a thorough understanding of habits and patterns of thinking in the foreign language, learners will not fully grasp the corresponding target language. Berkenkotter and Huckin (1995)[1] hold that understanding genres is crucial to take part in the practices of relevant discourse community. Bhatia (1997a, b)[2][3] adds that it is disastrous for authors to flout generic conventions. This is due to the fact that there are important differences between languages in the way in which discourse topic is identified and developed in terms of exemplification, definition and so on (Kaplan, 1987)[4]. Naturally, different languages have different preferences for certain kinds of discourse patterns. Many social cultural factors also influence the speakers' planning and communication performance. Poole (1991)[5] points out that discourse practices are usually culturally dependent on 
rhetorical value systems and reflect cultural beliefs and assumption.

Yayli Demet (2011: 121)[6] state that with the movement from structural approaches to language learning that support cognitive homogeneity of learners and their abstract cognitive or technical abilities in reading and writing toward communicative approaches that draw on how language is used to achieve social purposes in different contexts, genre and genre-based approaches have gained prominence in writing instruction (Hyland, 2007)[7]. Genre-based comparative analysis of public speeches given by native speakers and EFL learners has put genre and genre analysis to the most foregrounding position. Genre is thought of as referring to a socio-linguistic activity in which the participants are able to achieve particular goals. Obviously, it can be seen that communicative purposes are closely related with genre and analyses on genre. Miller (1984: 165)[8] suggests that "learning a genre is not simply about learning linguistic forms and conventions but also about learning how to participate in the actions of a community." To be specific, it will be about learning how to achieve communicative purposes in a more native-like manner for EFL learners. Genres have schematic structures, which in turn indicates that as instruments of rhetorical action, genres can have generative power (Himley, 1986)[9]. So acquiring proficiency in different genres involves an awareness of which discourse patterns are the most appropriate to the communicative context and purpose. Naturally, in different genres, the flexibility of obligatory and optional moves and steps in schematic structure of genre is quite dynamic and negotiable. The conventions of communicative moves and steps that speakers need to develop their main points and arguments might be diversified in specific realizations. Moves should be evident in the unified functional meaning of a sentence or group of sentences in a written or spoken discourse. Meanwhile, moves are also inseparable from a single unified communicative purpose in relation to the context in which they occur. In fact, the term schematic structure can simply refer to the staged and step-by-step organization of the genre. In other words, genres consist of a hierarchy of schematic structures, which are made up of moves and steps. Each stage in the genre contributes a part of the overall meanings that must be made for the genre to be accomplished successfully. It is conspicuous that moves and steps are available means by which communicative purposes can be realized in the specific discourses.

Move is a functional term which refers to a defined and bounded communicative act that is designed to achieve one main communicative purpose. However, they can either be obligatory or optional. Bhatia thinks that it is the very perspective of textual boundaries that "reveals the cognitive structures, typical or particular areas of enquiry" (1993: 19)[10]. Of course, in one specific discourse, all schematic structures have to be organized around one single central idea, during which process moves are used to achieve smaller communicative purposes. That's why Dudley Evans and St. John (1998)[11] insist that a move is a unit that relates both to the writer's purpose and to the content that he wishes to communicate, while a step is a lower text unit than the move in that it provides a detailed perspective on the options open to the writer in setting out the moves. In a word, genres should be identified by communicative purposes and the expected effects discourse participants intend to fulfill. On the other hand, schematic structures constituted hierarchically by moves and steps form the general structural frames for genres.

Martin and Rothery (1986)[12] state that genres specify conditions for beginning, continuing and ending a text. So it is with public speaking as a genre. In fact, every language possesses a structure which must at some level influence the way its users view the world (Carroll, 1956)[13] but genres form an open-ended set, which are not simply assemblies of more-or-less similar textual objects but instead, are coded and keyed events set within social communicative processes. Any message we transmit in the discourse, whether long or short, simple or complex is out of necessity structured, or organized in some way. Since we express only one idea at a time, we should always make a choice as to what to say first, second or last, and in doing so, we inevitably give the message a certain structure. In specific, any organized speech has a beginning, a development and an ending. Usually, they are labeled as the introduction, the discussion or body and the conclusion.

As the proverb goes "Well begun is half done". The introduction of a public speech should prepare the audiences for the whole speech and predict how the speech is going to be developed. Basically speaking, audience will be informed of what the speaker is going to talk about. Meanwhile, effective introduction will arouse the audiences' interest and attention immediately. At other times, the background information concerning the reason why the corresponding topic has been chosen can also be provided in the introduction part of the public speech. Then it comes to the body of the speech. It is the main part of the speech, the contents of which can support and develop the topic and fulfill the communicative purpose stated in the part of introduction by presenting reasons, solutions, exemplifications, elaborations and other relevant supporting materials. Generally speaking, because of the demands of logical and structural progression in a speech, the body of the speech can be divided into a few sections, which can be further divided into subsections if necessary. As the main part of the speech, many communicative devices can be used to achieve the maximum degree of effectiveness of the speech. Finally, in the conclusion part of the speech, main ideas are usually summarized or information and statement in the conclusion link back to the introduction, echoing with what has been stated in the introduction. Consequently, conclusion in the speech can complete the speech as an organic unity.

However, as for learners of a foreign language, they cannot separate the target language from their own culture nor can they distance themselves from native cultural norms 
of speaking. Learning a foreign language is just learning to coordinate the relationship between mother tongue and the target language, trying to carry out equivalent transformation between the linguistic codes. Sometimes, even though some foreign language learners have got enough communicative competence in foreign language, it is still inevitable that occasionally they have to depend on their mother tongue as an intermediary language for communication. Despite the language level of foreign language learners, when they cannot use their target language to fully express sophisticated problems, they usually have to resort to their mother tongue. However, it will be too absolute and abrupt to believe that EFL learners' speech writing should be transformed into the native way of English thinking. In accordance with those phenomena mentioned above, the paper will center on two research questions concerning features of macrostructure progression in public speech writing by different groups of English speakers and the corresponding significance for language teaching.

Question 1: How do schematic structures extend in public speech writing by native English speakers and EFL learners?

Question 2: How to deal with differences in schematic structures of public speech writing by native and nonnative English speakers in the teaching process?

Correspondingly, the study will on one hand analyze different ways of native English speakers and EFL learners in fulfilling their communicative purposes in their speech writing, concerning different features of schematic structures and explaining different ways of thinking; and on the other hand, it will discuss a reasonable way for the language teachers and learners to deal with the differences in schematic progression of information in the teaching process.

\section{Materials and Methods}

Subjects in the study are college students who are EFL learners in China and native English speakers in America. Besides, in accordance with the fact that the present study is comparative in nature between the two groups of English speakers, the standard and the criterion for the differentiation have been clarified. Moreover, the author has made full use of the available conditions in China concerning the collection of English speech materials. However, English speeches of EFL learners in China's universities can be easily recorded whereas English speeches given by native English speakers are not available within the same situation. Furthermore, simultaneous speeches will not be systematic enough to be analyzed. Based on these reasons, the author chooses published English speech materials for analysis, which refer to scripts of university students' prepared speeches in speech contests or classroom speeches concerning common issues in daily life and the degree of being formal can be considered mediate, being different from the quite formal inaugural speeches of presidents or the rather informal daily conversation. These materials are revised scripts of speeches presented by Chinese university students and native university students in America.

The paper selects dozens of speech scripts for analysis. To be specific, all the speech scripts by EFL learners are selected from "21st Century Cup" national English speech contest, which was originated by China Daily in 1996 and has been recognized as a most influential English speech competition in China. Considering the rigorous selection process before a final decision is made about who will be the contestants in the competition, it cannot be denied that these university students are proficient in both spoken and written English. Therefore, language proficiency will not be a prominent factor which can influence the validity of the study. However, as for the speech materials by native English speakers, it is not an easy task to find English public speeches with similar titles or subtitles as those of the speeches by EFL learners. Thus, in order to make sure the comparability, English speeches by native university students collected in the study share one common feature with those by EFL learners in China. In general, most of the speeches concern opinions of university students on important issues in their social life, such as youth obligation, teenage marriage, and independence in universities, feminist movement, mobile phone problem and so forth.

As for the process of data collection, the paper firstly classifies schematic structures of each speech script, specifically steps in each of the three moves (introduction, body and conclusion) into different types. Then frequencies of these classified steps are calculated in order to show the most popular strategies in speech introduction and speech conclusion applied by the two groups of English speakers in the process of genre constitution of public speeches. As for the feature analysis of speech bodies, the paper tends to give each move and step of the body a specific discourse function, such as transition, exemplification, elaboration and so on. By so doing, some regular discourse patterns in the speech bodies by different groups of English speakers can be observed for deeper analysis.

\section{Results of Data Collection}

\subsection{Public Speeches as a Genre}

Swales (2003: 46)[14] states that the principal feature that turns a collection of communicative events into a genre is some shared set of communicative purposes and genres are communicative vehicles for the achievement of goals. However, in reality, communicative purposes can be rather implicit and sometimes communicative purpose in a discourse might not be the primary criterion for the formation of specific genres. For example, poems and genres which mostly have appeals from verbal manipulation, such 
as public speeches discussed in the present paper are the representative evidences to show that communicative purposes, audiences and occasions can all be influential factors in the identification of a genre.

With regard to the identification of public speeches in the study as a genre, it can be observed that most of the public speeches selected in the study, which are made by native English speakers are argumentative and persuasive in nature. Of course, even in persuasive speeches, there are still some informative components. For instance, in the speech entitled "Cell Phones Indulge Arrogance of Youths", the beginning is an imaginative exemplification of a classroom situation concerning the ring of cell phones and the description is so detailed that vivid images appear immediately. In another speech entitled "The Effects of Poverty", there is also a similar illustrative part describing living conditions of a poor man. To some extent, it can be said that narrative parts in the speeches by native English speakers serve as foils to the remaining argumentative parts. As for the speeches by EFL learners, although the prepared topics seem to be argumentative and persuasive in nature, narration still occupies a large proportion with a typical example from the speech, whose subtitle is "Three Mirrors". Here, the speaker's main ideas are mostly supported by description of his uncle's stories. If the argumentative points in speeches by EFL learners are compared to be trunks, narrative parts are branches, whose luxuriance sustains the whole organization. Nevertheless, it is obvious that the communicative purpose in most of the speeches either given by native English speakers or by EFL learners in the study is to convince the audiences of the ideas and opinions of the speakers.

\subsection{Moves and Steps in the Schematic Structure of Public Speeches}

It is suggested that moves are determined partly by referencing from contexts and also by referencing to linguistic clues in the discourse. As a result, moves and steps can be identified and delimited through some linguistic signals that are important in deciding the boundaries of the moves, such as explicit prefacing, preparatory expressions and even discourse markers. Mirador (2000) [15] holds that moves exist within a structure and each move logically proceeds from and flows into another one. Correspondingly, the sequence of moves can be listed as Move 1, Move 2 and Move 3 (ibid). Moves together with steps, constitute schematic structures in a discourse, and steps are on the lower hierarchy of moves. In the study, the three basic constituent parts in English public speeches follow the sequential manner and is respectively entitled as Move 1 (Introduction), Move 2 (Body) and Move 3 (Conclusion). For a structurally complete public speech, the three moves are essential and obligatory but there can be a great degree of flexibility in steps of each move.

\subsubsection{Steps in Speech Introductions (Move 1)}

In the present study, the author has deliberately omitted analysis on the step in the opening remarks in the public speeches by EFL learners concerning greetings sent by the speakers to the chairpersons or judges in the speech contests for the sake of equivalent comparison. Introduction in the public speech has a number of functions. It can reveal the topic of the speech. It is such a basic requirement to state clearly the topic or focus of the speech in the introduction that speakers or audiences usually take it for granted. However, an effective introduction of a speech can get the attention and interest of the audiences and help to establish a favorable relationship between the speakers and their audiences. Besides, effective introduction will also provide background information of the speech so as to facilitate the audiences with the speakers' communicative purposes and focuses. Based on a comparative analysis of the introductions in public speeches given by native English speakers and EFL learners, data concerning the patterns of Introduction have been collected and are shown in Table 1.

Table 1. Proportions of Different Introduction (Move1) Patterns

\begin{tabular}{|c|c|c|}
\hline & $\begin{array}{c}\text { Speech Introductions } \\
\text { by Native English } \\
\text { Speakers }\end{array}$ & $\begin{array}{c}\text { Speech Introductions } \\
\text { by EFL Learners }\end{array}$ \\
\hline $\begin{array}{c}\text { Direct Reference to } \\
\text { the Subject }\end{array}$ & $22 \%$ & $11 \%$ \\
\hline Quotation & $17 \%$ & 0 \\
\hline $\begin{array}{c}\text { Reference to the } \\
\text { Audience }\end{array}$ & $17 \%$ & $44 \%$ \\
\hline $\begin{array}{c}\text { Background } \\
\text { Statement of } \\
\text { Subject and Purpose }\end{array}$ & $22 \%$ & $11 \%$ \\
\hline $\begin{array}{c}\text { Intriguing } \\
\text { Statement or } \\
\text { Rhetorical Question }\end{array}$ & $17 \%$ & $17 \%$ \\
\hline $\begin{array}{c}\text { Reference to the } \\
\text { Occasion }\end{array}$ & $5 \%$ & $11 \%$ \\
\hline Exemplification & 0 & $6 \%$ \\
\hline
\end{tabular}

Table 1 shows some language phenomena that cannot be ignored. Firstly, compared with those of EFL learners, native speakers' speech introductions are much more direct since a larger number of speeches start with direct reference to the subjects of the speech. Secondly, there are $44 \%$ of speech introductions in the study by EFL learners whose very beginning provides background statement of the subjects and purposes of the speech. Then, there is also one interesting phenomenon. That is, $17 \%$ of speech introductions by native English speakers begin with quotations whereas none in the nonnative English speakers' group. Finally, $11 \%$ of speech introductions by EFL learners immediately start with exemplification whereas there is none in the other group. Even though speech introductions by native English speakers also favor descriptive narration, there are some preludes to the succeeding step of exemplification.

Tracing back to the original speech materials, the quotation in one of the native English speeches is an idiom concerning parental education, "Let's go out of the apron strings"; quotation in another one is from Plato, "Democracy is from a fool's government", and there is one quotation 
from the supreme court justice, which claims, "There is insufficient evidence of a national consensus against executing mentally retarded people convicted of capital offenses for us to conclude that it is categorically prohibited by the Eighth Amendment". It is believable that quotations in the speech introductions can help to increase the credibility of the speeches and meanwhile function as an effective trigger for further discussion on important issues. However, comparatively speaking, EFL learners seem lack of resources of quotation.

\subsubsection{Steps in Speech Bodies (Move 2)}

The way in which we categorize experience through language shapes our ideas, beliefs, prejudices and even our aspirations. Roughly speaking, the manners we categorize experience correspond to the ways we offer proofs. From a comparative point of view, a further description of the genre, focusing on each individual cultural pattern, will be able to provide information of what is idiosyncratic or ethnic-related and what is universal and conventional to the genre. In Table 2 , the proportions of different progression patterns of speech bodies have been illustrated and meanwhile, comparison has been made between the two groups of English speakers.

Table 2. Proportions of Different Progression Patterns in Speech Bodies (Move 2)

\begin{tabular}{|c|c|c|c|c|}
\hline \multirow{3}{*}{ Topical Pattern } & \multicolumn{2}{|c|}{$\begin{array}{l}\text { Speech Bodies by } \\
\text { Native English } \\
\text { Speakers }\end{array}$} & \multicolumn{2}{|c|}{$\begin{array}{l}\text { Speech Bodies by } \\
\text { EFL Learners }\end{array}$} \\
\hline & $\begin{array}{c}\text { Logical } \\
\text { Progression }\end{array}$ & $22 \%$ & $\begin{array}{c}\text { Logical } \\
\text { Progression }\end{array}$ & $44 \%$ \\
\hline & $\begin{array}{l}\text { Random } \\
\text { Ordering }\end{array}$ & $26 \%$ & $\begin{array}{l}\text { Random } \\
\text { Ordering }\end{array}$ & $8 \%$ \\
\hline Refutative Pattern & \multicolumn{2}{|l|}{$6 \%$} & \multicolumn{2}{|l|}{$8 \%$} \\
\hline $\begin{array}{c}\text { Problem-Solution } \\
\text { Pattern }\end{array}$ & \multicolumn{2}{|l|}{$10 \%$} & \multicolumn{2}{|l|}{$4 \%$} \\
\hline Causal Pattern & \multicolumn{2}{|l|}{$13 \%$} & \multicolumn{2}{|l|}{0} \\
\hline $\begin{array}{l}\text { Rank-Order } \\
\text { Pattern }\end{array}$ & \multicolumn{2}{|l|}{$13 \%$} & \multicolumn{2}{|l|}{$8 \%$} \\
\hline $\begin{array}{c}\text { Comparison/Contr } \\
\text { ast Pattern }\end{array}$ & \multicolumn{2}{|l|}{$10 \%$} & \multicolumn{2}{|l|}{$12 \%$} \\
\hline $\begin{array}{l}\text { Chronological } \\
\text { Order }\end{array}$ & \multicolumn{2}{|l|}{0} & \multicolumn{2}{|l|}{$16 \%$} \\
\hline
\end{tabular}

According to Table 2, topical patterns are the most favorable among the two groups of English speakers. However, EFL learners seem to be more willing to apply logical progression in topical pattern whereas native English speakers instead are more skilled in using random ordering in topical pattern, which without any doubt, is superficially random but semantically tight in logical linkage. Distinctive proportions also cover problem-solution pattern, causal pattern, rank-order pattern and chronological order. Causal pattern, which is the frequent resort of native English speakers, seems to be a challenge that is never tried by the EFL learners. By contrast, chronological order which is a popular pattern in writing for EFL learners is abandoned by the native English speakers.

\subsubsection{Steps in Speech Conclusions (Move 3)}

Ending a speech is as important as beginning one. Sometimes, the climax of a speech just lies in the conclusion and what the audiences think of the speech can be much influenced by the closing remarks. As a consequence, an exquisite conclusion can always leave the audiences with a lingering and sensational impression. Specifically, while signaling the end, the obvious way is that speakers can use traditional expressions like, "in a word, in conclusion, in closing, finally" and so forth. Besides, some techniques are also available. For example, the main points in the speech can be restated and speakers can refer back to the introduction or even the body. They can end with expressions which are dramatically inspiring and memorable or end with a quotation. Conclusion patterns in speeches given by native English speakers and EFL learners are shown in Table 3.

Table 3. Proportions of Different Conclusion (Move 3) Patterns

\begin{tabular}{|c|c|c|}
\hline & $\begin{array}{c}\text { Speech Conclusions } \\
\text { by Native English } \\
\text { Speakers }\end{array}$ & $\begin{array}{c}\text { Speech Conclusions } \\
\text { by EFL Learners }\end{array}$ \\
\hline $\begin{array}{c}\text { Restatement of Main } \\
\text { Points }\end{array}$ & $28 \%$ & $22 \%$ \\
\hline $\begin{array}{c}\text { Appeal for Future } \\
\text { Actions }\end{array}$ & $22 \%$ & $6 \%$ \\
\hline $\begin{array}{c}\text { Intriguing and } \\
\text { Memorable } \\
\text { Statement }\end{array}$ & $17 \%$ & $16 \%$ \\
\hline Echo & $5 \%$ & $6 \%$ \\
\hline $\begin{array}{c}\text { Summary of the } \\
\text { Main Points }\end{array}$ & $17 \%$ & $11 \%$ \\
\hline Speakers' Volition & 0 & $6 \%$ \\
\hline Rhetorical Question & $11 \%$ & $6 \%$ \\
\hline $\begin{array}{c}\text { Combination of } \\
\text { Patterns }\end{array}$ & & $27 \%$ \\
\hline
\end{tabular}

As is show in Table 3, $6 \%$ speech conclusions are in the form of rhetorical questions, given by EFL learners. In comparison, there is none by native English speakers ended in such a manner. Similar situation also exists among speech conclusions given by EFL learners in terms of the speakers' volition. It can be considered as a traditional way of speech conclusion in Chinese. What should also be pointed out is that the number of speeches given by EFL learners ending with a combination of different patterns is far larger than that of the native group. Some speeches are ended with restatement of central ideas and appeal for future actions, or a summary of the theme and meanwhile appeal for future actions. Other speeches make reference to the current situations in the society and respectively, look into the future or show the speakers' volition. If an effective conclusion should make the speech an organic whole, giving the audiences an impression that the circle becomes complete at the very point, speech conclusions by both group of English speakers will fulfill the requirement but there is still a distinction of effects in reality. 


\section{Discussion}

\subsection{Discussion on Speech Introductions and Speech Conclusions}

Naturally, different arrangement of moves and steps will inevitably lead to different types of reasoning. Introduction, Body and Conclusion just constitute three broad moves of schematic structures in public speeches. Basically speaking, information covered in the speech introduction should be made appropriate to the speech subject and purpose, the audiences' background, attitudes and the occasion. At the very outset, speakers can just give immediate disclosure of their subjects and purpose. They can also bid for the attention of the audiences, or make a full explanatory introduction when they are to make a lengthy speech on a complex problem, resolution or bill. On the other hand, under the move structures of speech conclusions, many steps are applicable. Usually, the conclusion should at least play two roles. One is that it should inform the audiences that the speech is approaching to the end and the other is that it can reemphasize on the central ideas in the speech previously stated. Centering on the two basic roles, Conclusion in the genre of public speeches can be realized through diversified steps as have been revealed in Table 3. For example, in the summary conclusion, significantly important points of the speech are restated. Through a single and striking statement, an illusion, an example, a quotation, a maxim or a proverb, the inspiration of the public speeches to the audiences will be enhanced and the emotional appeal of the speeches to the audiences can also be intensified. Then audience will actively look at the speech subject in a certain way expected by the speaker and believe strongly in what is being urged by the speaker.

In the current study, when native English speakers make more direct reference to the subject, more reference to their audience or more intriguing statement or rhetorical questions at the beginning of their speeches, EFL learners tend to give more background statement of the speech subject and speech purposes and apply more examples. Besides, in speech conclusion, when native English speakers are good at appealing for future actions, EFL learners are more inclined to describe their volition and put forward rhetorical questions. Since there isn't an unanimous agreement on what is the most effective strategy in speech introduction, each of the two groups of English speakers will not be rashly criticized for being different from the other one. However, the stereotyped way of information organization in the introduction part of English writing by EFL learners in China has long been criticized as being lack of creativity and indefinite. For example, the sentence pattern of "with the development of ..., more and more ..." is very popular with EFL learners but students do not realize that it is a cliche and if they still insist on this way of opening their speech, they will lose a golden opportunity to give audience an alternative impression. When it comes to speech conclusion, EFL learners often find that apart from a conclusive remark on the main points covered in the speech body, they cannot think of other strategies that are easily applicable. Thus, they tend to follow the similar way of Chinese speech writing by expressing their determination or by asking a rhetorical question with purposes of motivating consensus or introspection among audience but they ignore the fact that persuasion requires reasoning, which is not simply realized by enumerating facts but by argumentation. Once EFL learners realize the subconscious influence of Chinese way of thinking in their English speech writing, it can be expected that they will not be as perplexed as before in handling speech conclusion. However, it doesn't mean that the Chinese culture-specific way of thinking should be rejected. When students are conscious enough to distinguish what is the Chinese norm of thinking and what is the English norm of thinking, they will be autonomous enough to decide which norm is the most applicable in specific contexts. If necessary, they can even combine the two norms together.

\subsection{Discussion on Speech Bodies}

Different thinking patterns of the two groups of English speakers will inevitably result in varied linguistic expressions and this is quite evidential in the speech bodies. The schematic structure of the speech body involves speakers' complicated conceptual work. Argumentatively, the body is concerned with the main realistic presentations of moves and steps. It will formally and systematically support the central statement in the speech by proving the divisions and subdivisions of the central statement. In short, for the speakers to be able to adapt the body of their speeches to the audience in their speeches, they must be divisions and subdivisions of the central statement that are both formally valid and semantically persuasive.

Moves can be identified by a combination of linguistic evidence and text comprehension. Based on linguistic clues, discourse can be divided into meaningful units, which naturally consist of both moves and steps in the schematic structures of a genre. Information in a discourse is richly and hierarchically structured but not just a static configuration of propositions. Usually, speakers will arrange a number of speech units into a most natural and logical order according to their own background and the purpose of their speeches. When concepts are formed, they must be arranged in sequences that make patterns. In fact, it is just this arrangement or ordering of concepts that makes up reasoning in the speeches even though the process of reasoning sometimes seems to be rather random. See the following two examples from the native English speech writing:

Move 2: Speech Body (1)

Step 1: Transitionary remark

Step 2: Statement of the speaker's standpoint

Step 3: Supportive exemplification

Step 4: Further elaboration 1 
Step 5: Effects

Step 6: Further elaboration 2

Step 7: Problems

Step 8: Further Elaboration 3

Move 2: Speech Body (2)

Step 1: "Sleepy" kids

Step 2: Kids who are late for school

Step 3: Cramming kids

Step 4: Day-dreamers

Step 5: Friendly kids

Step 6: Gangs

Step 7: Lovers

Although the arrangement of steps in the two speeches is random, the logic is not messy but ordered. The body of the first speech is ascending gradually to a climax where central ideas of the speech have been intensified to a prominent situation. On the other hand, in the body of the second speech, although the speech covers a wide range of contents, the boundaries among every step are clear enough to be identified since the whole speech has been delimited by transitionary words, phrases or even sentences between every two individual steps. Examples include: "And hand in hand with the sleepy kids is the kid who is late"; "And besides them there's the kid who's cramming"; "And besides them there is the day-dreamer"; "Then besides the day-dreamer there is the friendly kid" and so forth. Seemingly, the speaker is brainstorming and the audiences will never imagine what is going to be talked about next. But there is no difficulty in following the speaker's narration and discussion. By contrast, there are very few cases of random ordering in the speech bodies by EFL learners. Also, steps are relatively fewer than those in the bodies of the speeches by native English speakers. Take two EFL students' speech writing for example:

Move 2: Speech Body (3)

Step 1: Explanation with historical example

Step 2: Elaboration with examples from modern times

Step 3: Statement of the speaker's standpoint

Step 4: Further elaboration on the standpoint

(Speech entitled "Globalization: Challenges and Opportunities for China's Younger Generation")

Move 2: Speech Body (4)

Step 1: Foil for the theme of the speech

Step 2: Transitionary remark

Step 3: Elaboration on the theme

(Speech entitled "Vision of Peace-Fifteen Years on: Preparing for the Next Century")

EFL learners are more constrained by rules, so while presenting speeches, they cannot have wider horizon in elaborating opinions and what they are inclined to do is to follow the conventions in their mother tongue. Quite often, these linguistic behaviors happen in a subconscious manner. It seems that the more ideas speakers decide to use in a speech, the less effective each of them will be. Sharpest speakers will generally limit severely the number of ideas that require support and will support those selected carefully and powerfully until the audiences understand, believe, remember and are influenced by those carefully selected ideas. At the first glance, public speeches given by native English speakers tend to give us a misconception that they are messy with multifaceted facts or statements. However, when we go deeper into the schematic structures in those speeches, we will find that every move or step forms a link, which will be gradually bonded with other moves or steps. Sometimes, the order of linkage may not be so definite, thus demanding a little more effort of the audiences to interpret the communicative purposes of the speakers. Comparatively speaking, EFL learners tend to follow a seemingly prescribed order in organizing ideas in their speech bodies.

Even within the similar random ordering patterns of speech bodies, the effect of reasoning and the degree of persuasion are strikingly diversified between the speeches given by native English speakers and EFL learners. For example, in one of the EFL students' speech, the speaker wants to talk about the importance of peace, which, he believes is essential for prosperous life. However, it is almost in the middle of the body that the speaker makes his gist clear. He beats around the bush with detailed descriptions on the changes in his photo albums whereas even the elaborations on the theme sound like slogans. Most information in the speech is in a narrative manner, but those narrative steps cannot constitute sufficient persuasiveness in convincing people of the speakers' argumentation. In fact, all speeches are made up of facts, opinions and the interpretation of facts and opinions. Talking sense demands the ability to make accurate, reliable and convincing statement. It is reclusiveness of syntax and likewise of cognitive operations that makes it possible to build up complex information from parts that are basically relative to syntactically complex representations of information.

Generally speaking, it is believed that not only language but also logic and rhetorical patterns of discourse strategies of mother tongue will exert an overwhelming influence over students' spoken and written habits in a foreign language. Naturally, different languages have different preferences for certain kinds of discourse patterns. For example, English thinking pattern is usually from abstraction to concreteness whereas Chinese thinking pattern is just in the opposite direction, from concreteness to abstraction. In other words, based on this assumption, native English speakers tend to make summaries about the central ideas first and then put forward argumentative proofs and evidences afterwards. By contrast, Chinese foreign language learners of English will first of all offer supportive points to themes and then gradually state the themes in their speeches.

\subsection{The Interchangeability of Deductive Reasoning and Inductive Reasoning}

Communication is not only a process which enables people to share information, ideas or attitudes, but also one which can make use to send and receive ideas by means of 
verbal symbols. It can be considered a kind of transmission of information, which consists of several basic ingredients, including source, receiver, message, response and context. The five ingredients are interactive and complementary with each other, forming a dynamic communicative process. Correspondingly, in the communicative event of public speaking, every basic ingredient can find its counterpart. Of course, studying reasoning patterns in public speeches is just equivalent to studying on the message that is the speech contents in the communicative process of English public speeches.

Based on the data concerning schematic structures in the progression of the speeches given by native English speakers and EFL learners, it becomes clear that speech writing by native English speakers and EFL learners can be flexibly diversified concerning ways of reasoning. On one hand, there are many speeches offering supportive evidences to prove the conventionalized thinking pattern of English and of Chinese.

\section{Native English Speaker's Speech Writing}

\section{Move 1: Introduction}

Step 1: Introductory remark

Step 2: Statement of the speaker's standpoint

Step 3: Putting forward problems

\section{Move 2: Body}

Step 1: Explanation

Step 2: Further elaboration

Step 3: Transitionary remark

Step 4: Supportive point 1

Step 5: Supportive point 2

Step 6: Supportive point 3

Step 7: Effects of the problem

Step 8: Transitionary remark

Step 9: Elaboration on the problem

\section{Move 3: Conclusion}

Step 1: Appeal for future actions

Step 2: Restatement of the standpoint

\section{EFL Student's Speech Writing}

\section{Move 1: Introduction}

Step 1: Reference to the occasion

Step 2: Background statement of subject and purpose

\section{Move 2: Body}

Step 1: Transitionary remark

Step 2: One side's opinion

Step 3: The other side's opinion

Step 4: Explanation

Step 5: Further elaboration

Step 6: Summary of the main ideas

\section{Move 3: Conclusion}

Step 1: Restatement of the central idea

\section{Step 2: Memorable expression}

The two speeches are typical examples of thinking patterns in English and in Chinese. In Move 1 of the first speech, the general statement of the theme in the speech has been put forward and then all the steps in Move 2 are coordinating and even subordinating support for the theme. Finally, in Move 3, the central idea has been restated which echoes with the former part in the speech and forms a coherent semantic unity. On the other hand, in the second speech, main ideas come with the last step in Move 2 and most of the steps before the step of summary of main ideas have been supportive to the theme of the speech. Obviously, Chinese lays much emphasis on the completeness of content and meanings whereas English tends to pay more attention to the completeness in structure and compactness in forms. However, there are also other different evidences, which indicate that the concept of being inductive or deductive is dynamic and changeable. The progression of the schematic structures in another two speeches is evidential enough to prove the aforementioned.

\section{Native English Speaker's Speech Writing}

\section{Move 1: Introduction}

Step 1: Introductory information

Step 2: Elaboration on the title

\section{Move 2: Body}

Step 1: Positive phenomena

Step 2: Negative phenomena

Step 3: Problem rising

\section{Move 3: Conclusion}

Step 1: Statement of the theme

Step 2: Solution to the problem

\section{EFL Student's Speech Writing}

\section{Move 1: Introduction}

Step 1: Introductory remark

Step 2: Putting forward the subject

Step 3: General statement of the theme

\section{Move 2: Body}

Step 1: Explanation

Step 2: Elaboration

Step 3: Further elaboration

\section{Move 3: Conclusion}

\section{Step (1): Restatement of the central idea}

This time, public speech by native English speakers becomes inductive whereas speech by EFL learners is deductive instead. In fact, speech can be considered as a structural organ and a sophisticated construction. Moves and steps in the schematic structures can be either obligatory or optional. The feature of being obligatory can ascribe a genre as belonging to a particular genre while optionality gives 
varieties to the structural resources within a genre. As what has been shown in the speech examples selected for comparative illustration, flexibility in steps can make reasoning patterns in the same language diversified. In the present study, public speeches have been taken as a special genre where the three moves-Introduction, Body and Conclusion are inevitably obligatory but those steps under every move are comparatively optional. However, there has always been a step for the statement of the speaker's central ideas or standpoints. Its position is rather flexible among the three moves. It can be in Move 1 or Move 2 or Move 3 without fixed arrangement.

\section{Conclusions and Implications}

Generally speaking, to be fluent in a foreign language requires not only mastery of its grammatical rules but also competence in the appropriate use of sentences that are structured by the rules. Fluency is supposed to possess two distinct kinds of competence including the knowledge of how to form sentences and then the knowledge of what those sentences are capable of doing and when and how to use them appropriately. In foreign language teaching, the training of speaking should not be simply concentrated on grammar but teachers should lay equal emphasis on analyses on genre, pedagogies based on which can promise very real benefits for learners as they pull together language, content and contexts, while offering teachers a means of presenting students with explicit and systematic explanations of the ways writing works to communicate (Christie \& Martin, 1997)[16]. Foreign language learning is a demanding experience, constituting a great challenge to learners' communicative competence. Classroom applications of genre are an outcome of communicative approaches to language teaching which emerged in the 1970s, continuing a pedagogic tradition of stressing the role language plays in helping learners achieve particular purposes in context (Hyland, 2004)[17]. Students' sensitivity and ability in identifying communicative purposes in specific genres can be considered as their discourse competence. However, there should not be any static rule for language learners to follow concerning the application and arrangement of schematic structures. It can be observed from the study that even in the public speeches by native English speakers, there is a great flexibility and fluidity in the ordering of ideas and structures, which has added to the speeches much impressiveness. As a consequence, while teaching students English speeches, teachers should enlarge students' field of vision. At first, teachers can show simple examples of those schematic patterns and structural ordering. With students' increasingly deep-going understanding on the functions of those patterns and structures, teachers can gradually guide them into a little more sophisticated arrangement of facts, ideas and statements in their speeches. For example, students can learn to combine several different structural patterns together with logical ordering. Although the three moves of Introduction, Body and Conclusion are obligatory, most of the steps within the hierarchy of moves are optional. Language learners are individuals who approach foreign language learning in their unique ways, so teachers should leave them with appropriate freedom and larger space for creativity. In other words, instead of telling EFL learners what to do exactly, language teachers can tell students how to do, that is, how to apply different steps to create special discourse effect, which in public speech scripts, mainly refers to the persuasiveness.

Kaplan (1966)[18] describes the structure of English exposition as linear because a paragraph in English typically begins with a topic statement supported by examples that are related to the central theme. In other words, native English speakers tend to develop their ideas in the speeches from generalization to the specific and from abstraction to concreteness whereas the logical manner of EFL learners in China will usually be the opposite. As in Kaplan's belief, the oriental way of thinking is spiral. However, the findings in the study indicate that the Chinese culture-specific patterns of organization do not exert negative influence in students' EFL writing, especially the body part of the speech. Some EFL learners put forward their central ideas at the very beginning of their public speeches and then offer specific supportive details or explanations to prove the theme. By contrast, some native English speakers make summaries about the theme and central ideas almost at the end of the public speeches. Obviously, the general statement of central ideas and theme do not have fixed positions, and evidences have shown that they can appear within any move of the public speeches.

Undoubtedly, Introduction, Body and Conclusion are obligatory moves in the public speeches. In other words, without any of them, the speech will not be complete as a specific genre. On the other hand, there is a great flexibility allowable among different steps applied in the speeches. In the introductions of the speeches, there are statements to attract audience's attention; a startling statement to arouse their interest and suspense; a quotation to certify the speakers' standpoint; a reference to the audience, subject or occasion; an exemplification; an intriguing statement or rhetorical question; a statement to enhance credibility, statements of importance or statements providing background of subject and purpose. Then in the organization of the bodies of the speeches, many patterns have been applied, including chronological pattern, rank-order pattern, refutative pattern, problem-solution pattern, alternative pattern, comparison and contrast pattern and topical pattern. Finally, in the conclusions of the public speeches, speakers also have many choices, like restating the main points, referring back to the introduction or former parts of the speeches, ending with expressions which are dramatically inspiring and memorable, or ending with quotations. Inevitably, the two groups of speakers of English tend to be diversified in choosing what to speak first, second and third, and specifically in what manner and order. That is why there 
have been conspicuously different data concerning proportions of different steps, as have been shown in the tables. It can be said that most of the speech materials in the study are both informative and persuasive in nature and any intentional schematic arrangement of moves and steps can indeed result in different gradation in informativity and persuasion in those speeches.

Correspondingly, research findings in this comparative study can provide some enlightenment in foreign language teaching. In recent years, English speech contests have gained increasing popularity in China, especially among university students, and nationwide speech contests like "21st Century Cup" and "FLTRP Cup" have been widely held each year throughout the country. Thus, studies on skills and strategies concerning public speeches will of course have realistic significance in the improvement of public speaking by EFL learners in China. Since certain types of interactional practices, specifically those in which participants can focus their attention on linguistic forms may promote language learning, public speeches can be an efficient resort for language teaching and learning. Comparative analysis will just offer learners insights into native ways of English speeches, which will further stimulate both language teachers and students to be sensitive to specific cultural and linguistic phenomena in Chinese and English and gradually develop their intercultural communicative competence which is defined by Stephen E. Lucas (2012: 6)[19] as "the ability to respect diversity and to communicate effectively in cross-cultural situations". In other words, following the Chinese way of thinking, such as the inductive way of reasoning, will not hinder EFL learners from becoming competent English speakers. When speech introductions and speech conclusions by EFL learners are comparatively lack of persuasive force, it is actually not the culture-specific step strategies but language itself that is the main reason. Thus, public speaking is a comprehensive subject which should lay equal emphasis on speaking skills at the vocal level, schematic structures at the genre level and some lexical, syntactic and rhetorical aspects at the language level (Chang Wang, 2014)[20]. Different perspectives are mutually influential and cannot be separated.

McLaughlin and Moore (2012:158)[21] hold that without open-minded thinking as a basis of approaching the writing task, the writer may not achieve the level of reasoning that is expected. So developing EFL students' open-mindedness in conceiving persuasive ideas in their speech writing will be of prior importance during the educational process. The main task for language teachers in teaching the course of public speaking is to unfold a world of creative arrangement of schematic structures which are featured by different culture-specific norms of thinking, encourage students to try different discourse patterns and finally help them to autonomously create their own effective schematic structures in accordance with different speech topics, purposes and contexts.

\section{Acknowledgments}

This paper is funded by "The Fundamental Research Funds for the Central Universities in People's Republic of China". It is one of the results of "Training Project of English Majors' Critical Thinking-Take Writing Course as the Dimension" (No.XQ15020) and "Study on Construction Strategies of Logico-Semantic Relations in University Students' EFL Writing” (No. 14ZZ2118).

\section{REFERENCES}

[1] Berkenkotter, C., \& Huckin, T. N. (1995). Genre Knowledge in Disciplinary Communication: Cognition/Culture/Power. Lawrence Erlbaum, Hillsdale, NJ.

[2] Bhatia, V. K. (1997a). Introduction: genre analysis and world Englishes. World Englishes, 16(3): 313-319.

[3] Bhatia, V. K. (1997b). The Power and Politics of Genre. World Englishes, 16(3): 359-371.

[4] Kaplan, R. (1987). Three seductions of computational psycholinguistics. In P. Whitelock, M. M. Woods, H. L. Somers, R. Johnson, \& P. Bennett (Eds.), Linguistic theory and computer applications (pp. 149-188). London: Academic Press.

[5] Poole, D. (1991). Discourse analysis in ethnographic research. Annual Review of Applied Linguistics, 11: 42-56.

[6] Yayli, D. (2011). From genre-awareness to cross-genre awareness: A study in an EFL context. Journal of English for Academic Purposes, 10:121-129.

[7] Hyland, K. (2007). Genre pedagogy: language, literacy and L2 writing instruction. Journal of Second Language Writing, 16:148-164.

[8] Miller, A. B. (1984). Modes of Public Speaking. California: Wadsworth Publishing Company.

[9] Himley, M. (1986). Genre as generative: One perspective on one child's early writing growth. In M. Nystrand (Ed.), The Structure of Written Communication: Studies in Reciprocity between Writers and Readers. Orlando, FL: Academic Press.

[10] Bhatia, V. K. (1993). Analyzing Genre: Language use in professional settings. London: Longman.

[11] Dudley-Evans, A. \& St. Jones, M. (1998). Developments in English for specific purposes. Cambridge, UK: Cambridge University Press.

[12] Martin, J. R., \& Rothery, J. (1986). What a Functional Approach to the Writing Task Can Show Teachers about 'Good Writing'. In B. Couture (Ed.), Functional Approaches to Writing: Research Perspectives (pp. 241-265). London: Frances Pinter.

[13] Carroll, J. (Ed.). (1956). Language, Thought and Reality: Selected writings of Benjamin Lee Whorf. Massachusetts Institute of Technology. 
[14] Swales, J. M. (2003). Genre Analysis: English in academic and research settings. Cambridge: Cambridge University Press.

[15] Mirador, J. (2000). A move analysis of written feedback in higher education. RELC Journal, 31: 45-60.

[16] Christie, F., \& Martin, J. R. (Eds.). (1997). Genre and institutions: Social processes in the workplace and school. London: Pinter.

[17] Hyland, K. (2004). Genre and second language writing. MI: University of Michigan Press.

[18] Kaplan, R. B. (1966). Cultural Thought Patterns in intercultural education. Language Learning, 16(1): 1-20.

[19] Lucas, S. E. (2012). The Art of Public Speaking. Beijing: Foreign Language Teaching and Research Press.

[20] Wang, C. (2014). Contrastive Analysis of Microstructures in Public Speeches by Native and Nonnative English Speakers. In: L. Hale, J. Zhang, \& F. Qi (Eds.), Proceedings of the Third Northeast Asia International Symposium on Language, Literature and Translation (Volume II) (PP. 499-504). New York: The American Scholars Press.

[21] MacLaughlin, F., \& Moore, M. (2012). Integrating critical thinking into assessment of college writing. Teaching English in the Two-Year College, 40(2): 145-162.

\begin{abstract}
i This article makes a comparative genre analysis of macrostructures in public speeches by native and nonnative English speakers, succeeding another article entitled Contrastive Analysis of Microstructures in Public Speeches by Native and Nonnative English Speakers, which has been published in Proceedings of the Third Northeast Asia International Symposium on Language, Literature and Translation (2014:499-504) and mainly focuses on language features of university students' speech scripts, including lexical choices, discourse markers and rhetorical devices. It is found that the three language features can respectively influence the style, logic and forcefulness in public speeches.
\end{abstract}

